American Journal of Pharmacology and Toxicology 5 (2): 71-79, 2010

ISSN 1557-4962

(C) 2010 Science Publications

\title{
Cardiac Depression Produced by L-Arginine and Phosphodiestrase Inhibitor on Isolated Mammalian Rabbit Heart: Function of Cyclic Guanosine Monophosphate (cGMP)
}

\author{
${ }^{1}$ Hussein F. Sakr, ${ }^{1}$ Fahaid Al-Hashem, ${ }^{1}$ Mahmoud Al-Khateeb, \\ ${ }^{2}$ Abdullah S. Shatoor and ${ }^{3}$ Mamdoh Eskandar \\ ${ }^{1}$ Department of Physiology, \\ ${ }^{2}$ Department of Internal Medicine (Cardiology Section), \\ ${ }^{3}$ Department of Obstetrics and Gynaecology, \\ College of Medicine, King Khalid University, Abha 64121, Saudi Arabia
}

\begin{abstract}
Problem statement: Cyclic guanosine 3',5'-monophosphate cGMP is one the important second messengers that determines the cardiomyocyte activity and its role in healthy and diseased cardiac muscle is still controversial. We are reporting the effect of adding L-arginine, the NO donor that stimulates cGMP production and Sildenafil citrate (phosphodiestrase inhibitor) that inhibits cGMP hydrolyis on isolated rabbit's heart to answer: Is it safe to prescribe phosphodiestrase inhibitors for men with low cardiac output? Approach: Isolated hearts from 6 rabbits were perfused using Langendorff's apparatus in which the perfusion fluid was ringer-Locke solution, applied at constant flow rate and was continuously bubbled with a mixture of $95 \%$ oxygen and $5 \%$ carbon dioxide. Each heart served as its own control before infusion of L-arginine in concentration of $3 \mathrm{~m} \mathrm{~mol} \mathrm{~L}^{-1}$ and Sildenafil citrate $1.5 \mathrm{mg} \mathrm{L}^{-1}$ simultaneously. Their effects were recorded after 1, 3, 5 and $10 \mathrm{~min}$. The effluent fluid was collected for cardiac enzymes assay after 5 and 10 min. Results: Data showed that the infusion of L-arginine and Sildenafil citrate produced negative inotrpic and chronotropic effects. Also, the cardiac enzymes were significantly elevated. Conclusion: The present study, which was carried out on the isolated rabbit's heart, demonstrated that increased cGMP could produce a cardioprotective role by decreasing the cardiac work, although it might be hazardous to men with depressed cardiac function.
\end{abstract}

Key words: cGMP, L-arginine, sildenafil citrate, isolated mammalian heart

\section{INTRODUCTION}

Cyclic Guanosine monophosphate (cGMP) is a second messenger signaling molecule (Ashman et al., 1963) which is generated from the cytosolic purine nucleotide Guanosine Triphosphate (GTP) by two distinct enzymes: The cytoplasmic heterodimeric haemoprotein s-Guanylate Cyclases (sGC) which is activated by Nitric Oxide (NO) and Carbon monoxide (CO); And the transmembrane receptor particulate Guanylate Cyclases (pGCs, GC or Natriuretic Peptide Receptor (NPR) that act as functional receptors for the natriuretic peptides (Lucas et al., 2000; Feil et al., 2003; Hussain et al., 2001; Kuhn, 2004).

Nitric Oxide (NO) is produced from L-arginine by a family of enzymes known as NO Synthases (NOS).
Cardiac muscle fibers and coronary vascular beds express the enzyme endothelial NOS (Balligand et al., 1995). NO activate sGC via different mechanisms: it directly binds the ferrous core of the enzyme, which leads to creation of a protoporphyrin IX-like structure (a potent activator of $\mathrm{sGC}$ ). Oligomerization and phosphorylation enables the extracellular binding domains of pGC to remain in a high-affinity state, thus priming the cytoplasmic domain to respond to ligand receptor interaction. GTP binds to a single catalytic site on sGC and two catalytic sites on pGC. The $\alpha$ - and $\beta$ subunits of the guanylate cyclases cause cleavage of the $\alpha$-phosphoanhydride bond of GTP yielding cGMP and pyrophosphate (Lucas et al., 2000).

Sildenafil citrate (Viagra) is a selective inhibitor of cGMP-specific Phosphodiesterase type 5 (PDE5) and is

Corresponding Author: Hussein F. Sakr, Department of Physiology, College of Medicine, King Khalid University, Abha 64121, Saudi Arabia 
indicated for the treatment of erectile dysfunction. The physiological mechanism responsible for erection of the penis involves the release of $\mathrm{NO}$ in the corpus cavernosum in response to sexual stimulation. NO activates the enzyme guanylate cyclase, which results in locally increased levels of cGMP, thereby producing smooth muscle relaxation. By inhibiting PDE5, sildenafil citrate enhances the normal physiological action of NO and cGMP, thereby allowing patients to attain erection adequate for sexual intercourse (Jeremy et al., 1997).

At least three classes of proteins bind cGMP and facilitate its signal transduction roles: cGMPdependent protein kinases or Protein Kinase-G (PKG), the cGMP-regulated Phosphodiesterases (PDEs) and the CNG (Su et al., 2005).

In the mammalian cardiovascular system, the biological actions of elevated intracellular concentration of cGMP are numerous and diverse. They include vascular smooth muscle relaxation; regulation of ion transport, contributing to electrolyte/ion homeostasis and vascular cell permeability; inhibition of platelet activation mechanisms; regulation of cell growth, differentiation and apoptosis; and cardiac myocyte contractility (inotropy) (Kojda and Kottenberg, 1999; Feil and Kemp-Harper, 2006). These effects in the cardiovascular system are in part attributable to the principal intracellular mediator of cGMP, PKG and in part due to alterations in cAMP and Cyclic Nucleotide Gated (CNG) channel activity (Kuo et al., 1970; Lohmann et al., 1997; Lincoln et al., 2001; Wall et al., 2003). Thus, the aim of the present study is to clarify the role of increased cGMP on isolated mammalian heart.

\section{MATERIALS AND METHODS}

Adult 6 male rabbits weighing between $2-3 \mathrm{~kg}$ were used for the experiments. Approval was obtained from the faculty of medicine ethical committee, King Khalid University, Abha, Saudi Arabia. The animals were obtained from the animal house of the department physiology at King Khalid University where they were fed with standard rabbit pellets and allowed free access to water. They were housed at a controlled ambient temperature of $25 \pm 2{ }^{\circ} \mathrm{C}$ with $50 \pm 10 \%$ relative humidity and with a $12 \mathrm{~h}$ light/12 h dark cycle. All studies were conducted in accordance with the National Institute of Health's Guide for the Care and Use of Laboratory Animals (National Institute of Health, 1996).
Preparation of the isolated hearts: This experiment was carried out in accordance with the Langendorff (1895) procedure. A rabbit was injected with 1000 IU of heparin intravenously through the marginal ear vein. Five minutes later, the rabbit was sacrificed, dissected and the heart with about $1 \mathrm{~cm}$ of the aorta attached, was removed as quickly as possible and transferred into a Petri-dish containing Ringer-Locke solution $(\mathrm{NaCl}$; $45.0 \mathrm{~g}, \mathrm{NaHCO}_{3} ; 1.0 \mathrm{~g}$, D-glucose; $5.0 \mathrm{~g}, \mathrm{KCl} ; 2.1 \mathrm{~g}$, $\mathrm{CaCl}_{2} \cdot 2 \mathrm{H}_{2} \mathrm{O} ; 1.6 \mathrm{~g}$, in $5 \mathrm{~L}$ of distilled water). The heart preparation was gently squeezed several times to remove as much of residual blood as possible. The aorta was cut just below the carotid bifurcation. The heart was transferred to the perfusion apparatus and tied to the glass canula. The perfusion fluid was Ringer-Locke solution, which was continuously bubbled with a mixture of $95 \%$ oxygen and $5 \%$ carbon dioxide. The fluid was applied at constant flow rate from a reservoir maintained at $37^{\circ} \mathrm{C}$ by water circulated through thermostated water bath at rate range of 8-12 $\mathrm{ml} / \mathrm{minute} / \mathrm{g}$ wet weight of tissue.

Recording of contractility and heart rate: The response of the drugs was recorded on a student a Narco Bio physiograph (MKIII- S, Narco Bio Systems, USA) by attaching on of end of thread to the apex of the heart by means of palmer clip and the other end of the thread to a force transducer (P- 1000B; Narco Bio Instruments) after passing it through 2 pulleys. The speed of the study of the physiograph was fixed at $0.25 \mathrm{~cm} \mathrm{sec}^{-1}$. Contractility was measured as the mean height in $\mathrm{mm}$ of 4 cardiac contractions spikes and heart rate as the number of beats per min. During the experiments each heart served as its own control before injection of each solution.

Protocol of experiment: Adrenaline was given before the beginning of the experiment procedure to record the sensitivity of the heart. L-arginine in concentration of $3 \mathrm{mmol} \mathrm{L}^{-1}$ and sildenafil citrate in $1.5 \mathrm{mg} \mathrm{L}^{-1}$ was infused to the isolated mammalian heart. The speed of the study of the physiograph was fixed at $0.25 \mathrm{~cm} \mathrm{sec}^{-1}$. Contractility was measured as the mean height in $\mathrm{mm}$ of 4 cardiac contractions spikes and heart rate as the number of beats per min. During the experiments each heart served as its own control before infusion of each solution.

Biochemical measurements: The effluent was collected during the infusion and analyzed for Creatine Kinase (CK), Lactate Dehydrogenase (LDH) and Aspartate Transaminae (AST). The levels of these 
enzymes were measured using commercial available kits according to the manufactures instruction (human co.).

Statistical analysis: All data obtained were statistically analyzed using students' t-test. The data were expressed as average mean $\pm \mathrm{SD}$ and values of $\mathrm{p}<0.05$ were considered significant.

\section{RESULTS}

Table 1, Fig. 1 and 3 show that continuous infusion of L-arginine and Sildenafil citrate produced a significant decrease in heart rate after $1,3,5,7$ and $10 \mathrm{~min}$ $(p<0.0001)$ with the percent of inhibition of $47.7,75.44$, $83.04,88.04$ and $94.78 \%$ respectively.

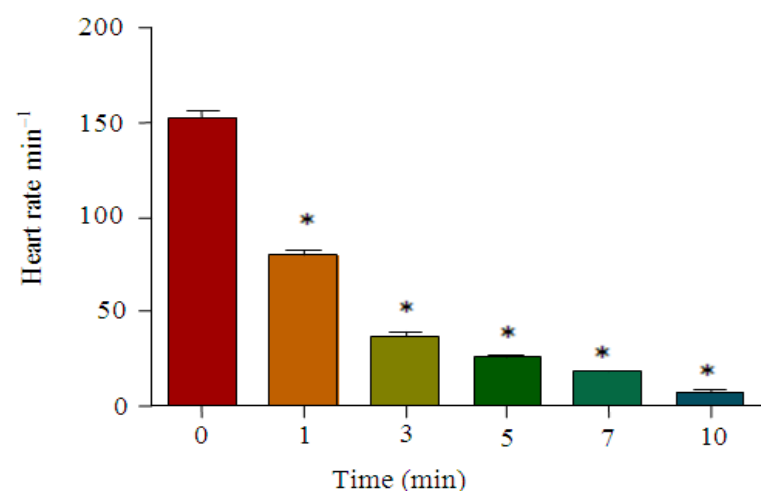

Fig. 1: Negative chronotropic effect produced by combined infusion of L-arginine and Sildenafil citrate. Values are given as mean $\pm \mathrm{SD}$ for a group of 6 animals
Table 2, Fig. 2 and 3 show a significant reduction in the amplitude of contraction measured in $\mathrm{cm}$. $(p<0.0001)$ with the continuous infusion of L-arginine and Sildenafil citrate. The percent of decrease in contractility was $48.31,59.55,68,54$ and $76.40 \%$ after 1,3 5 and $10 \mathrm{~min}$ respectively.

The level of cardiac enzymes AST, CK and LDH were significantly increased as shown in Table 3 after $10 \mathrm{~min}$ of L-arginine and sildenafil citrate infusion when compared to their level in the effluent after $5 \mathrm{~min}$ of the infusion. The percent of increase of AST, CK and $\mathrm{LH} \mid$ is 17.46, 12.46 and $14.29 \%$ respectively.

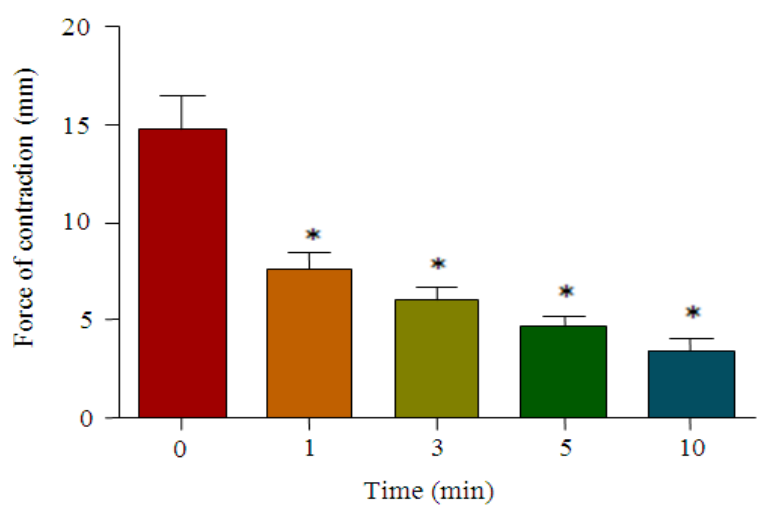

Fig. 2: Negative inotropic effect produced by combined infusion of L-arginine and Sildenafil citrate. Values are given as mean $\pm \mathrm{SD}$ for a group of 6 animals

Table 1: The effect of continuous infusion of L-arginine and Sildenafil citrate on the heart rate (beat $\min ^{-1}$ ), recorded after $1,3,5$ and $10 \mathrm{~min}$

\begin{tabular}{|c|c|c|c|c|c|c|}
\hline & Control & $1 \mathrm{~min}$ & $3 \mathrm{~min}$ & $5 \mathrm{~min}$ & $7 \mathrm{~min}$ & $10 \mathrm{~min}$ \\
\hline Mean \pm SD & $153.33 \pm 7.96$ & $80.5 \pm 5.78^{*}$ & $37.66 \pm 2.94^{*}$ & $26 \pm 2.52 *$ & $18.33 \pm 1.96^{*}$ & $8 \pm 2.52 *$ \\
\hline Percentage of decrease & & 47.5 & 75.43 & 83.04 & 88.04 & 94.78 \\
\hline
\end{tabular}

Values are given as mean \pm SD for a group of 6 animals. Values are statistically significant at $*$ p $<0.05$ when compared with control

Table 2: The effect of continuous infusion of L-arginine and Sildenafil citrate on the amplitude of contraction (mm), recorded after 1, 3, 5 and $10 \mathrm{~min}$

\begin{tabular}{lllll}
\hline & Control & $1 \mathrm{~min}$ & $3 \mathrm{~min}$ & $5 \mathrm{~min}$ \\
\hline Mean \pm SD & $14.83 \pm 1.72$ & $7.66 \pm 0.81^{*}$ & $6.0 \pm 0.63^{*}$ & $4.66 \pm 0.51^{*}$ \\
Percentage of decrease & & 48.31 & 59.55 & $3.5 \pm 0.54^{*}$ \\
\hline
\end{tabular}

Values are given as mean \pm SD for a group of 6 animals. Values are statistically significant at $* \mathrm{p}<0.05$ when compared with control

Table 3: The effects of combined infusion of L-arginine and Sildenafil citrate after 5 and 10 min on the level of the cardiac enzymes

\begin{tabular}{llll}
\hline & AST $\left(\mathrm{U} \mathrm{L}^{-1}\right)$ & $\mathrm{CK}\left(\mathrm{U} \mathrm{L}^{-1}\right)$ & $\left.\mathrm{LDH}(\mathrm{U} \mathrm{L})^{-1}\right)$ \\
\hline 5 min infusion & $19.30 \pm 0.81$ & $251.5 \pm 9.34$ & $27.0 \pm 2.82$ \\
10 min infusion & $22.67 \pm 0.81 *$ & $287.3 \pm 7.28 *$ & $31.5 \pm 2.67 *$ \\
\hline
\end{tabular}

Values are given as mean \pm SD for a group of 6 animals. Values are statistically significant at $* \mathrm{p}<0.05$ when compared with control 
Am. J. Pharm. \& Toxicol., 5 (2): 71-79, 2010

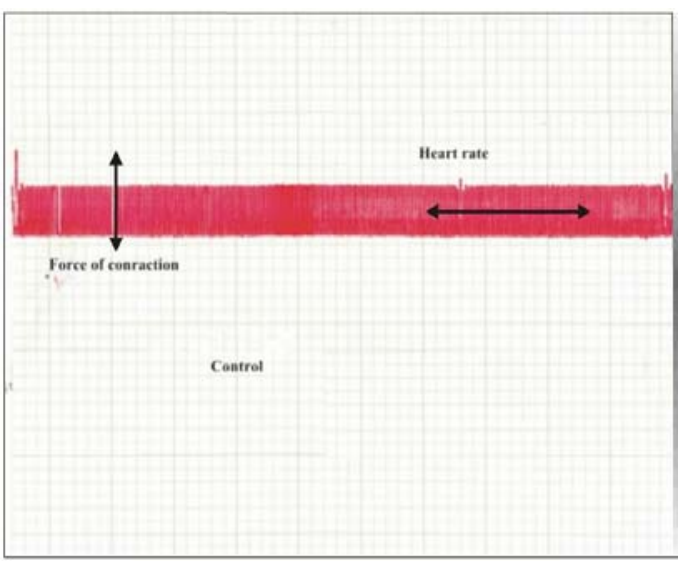

(A)

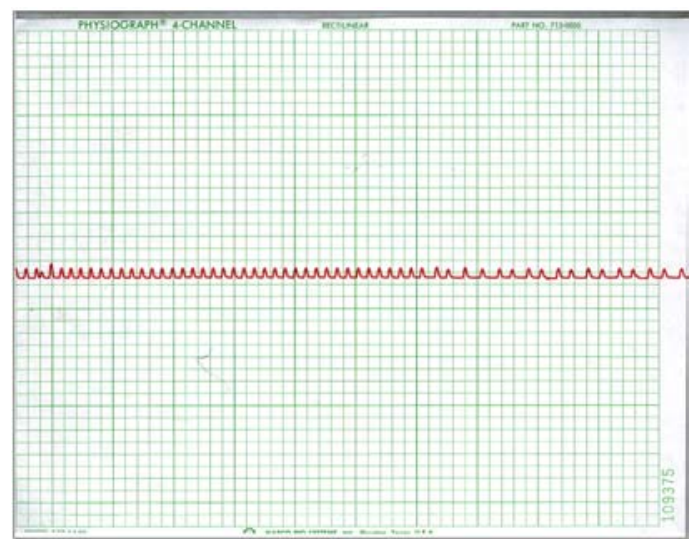

(C)

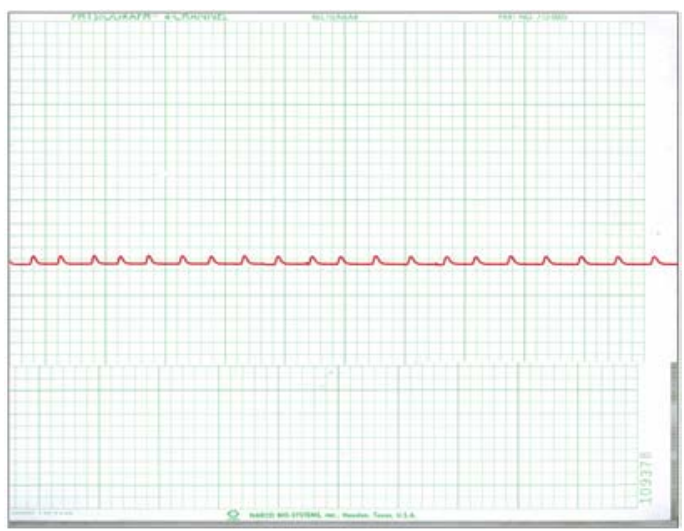

(E)

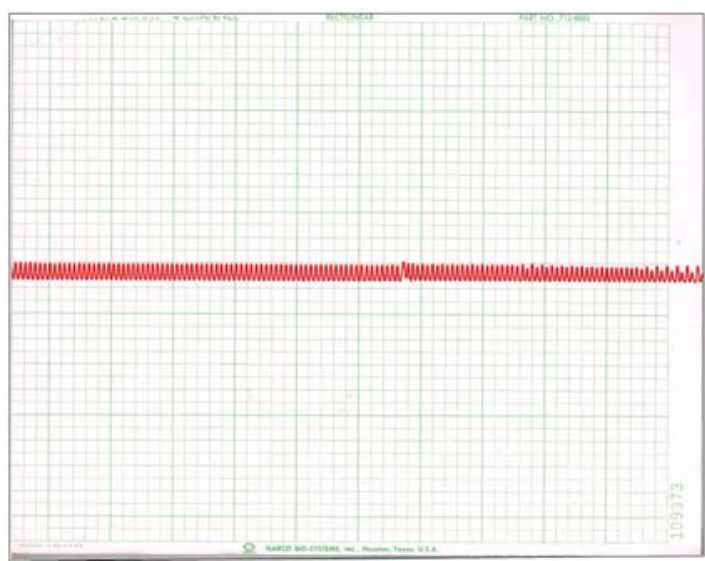

(B)

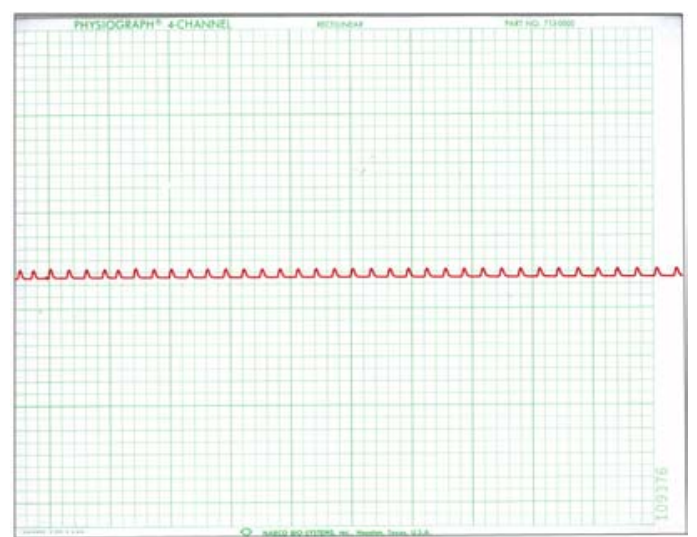

(D)

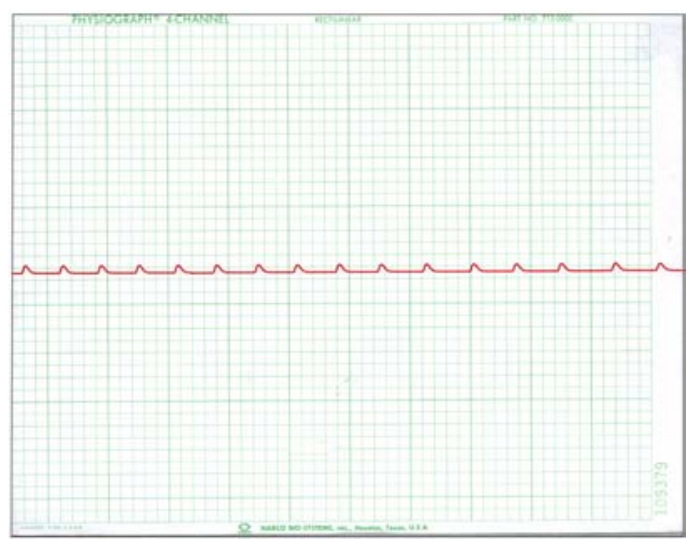

(F)

Fig. 3: Negative inotropic and chronotropic effects of L-arginine and sildenafil citrate on isolated rabbit's heart; (A) Control; (B) Recording after 1 min; (C) Recording after 3 min; (D) Recording after 5 min; (E) Recording after $7 \mathrm{~min}$; (F) Recording after $10 \mathrm{~min}$

\section{DISCUSSION}

L-arginine is the NO precursor which is utilized by the constitutive endothelial NO syntheses to yield NO within the cardiomyocyte. NO stimulates guanylate cyclase, which in turn increases intracellular cGMP levels. Also, the 5' phosphphdiestrase inhibitors produce accumulation of cGMP. At least three classes of proteins 
bind cGMP and facilitate its signal transduction roles: cGMP-dependent protein kinases or Protein Kinase-G (PKG), the cGMP-regulated Phosphodiesterases (PDEs) and the CNG (Su et al., 2005).

The infusion of L-arginine and sildenafil citrate induces cardioinhibitory effects in the isolated denervated heart. Previous studies reported that cGMP has controversial effects on the cardiac muscle.

In our study, the continuous infusion of Larginine and sidenafil produces inhibition of both rhythmicity and contractility as postulated in Table 1 and 2. The negative inotropic and chronotropic effects were postulated by several mechanisms.

The rhythmicity of the cardiac muscle is controlled by the spontaneous generation of cardiac action potential from the slow cardiomyocytes located in the Sino-Atrial node. The mechanism of the automatic generation of the cardiac impulse is dependent on various ion channels located in the membrane of the SAN. The diastolic prepotential is mainly caused by the slow inward $\mathrm{Na}^{+}{ }_{(\mathrm{f})}$ current through the funny channels and also by the $i_{\mathrm{K} 1}$ (inward rectifier). Prolongation of the prepotential slows the heart rate. Also, the heart rate can be slowed by the excess $\mathrm{K}^{+}$efflux through acetyl cholin $\mathrm{K}^{+}$channels producing hyperpolarization of the SAN membrane. The negative chronotropic effects were detected by the gradual decreased heart rate with continuous infusion.

Possibly the inhibitory effects of the NO is mediated through cGMP which control ATP sensitive $\mathrm{K}^{+}$channels which increases $\mathrm{K}^{+}$permeability when the ATP is low, cGMP reduces myocardial oxygen consumption (Weiss et al., 1994) and therefore deceases ATP synthesis (Ockaili et al., 1999). Interestingly, cGMP also blocks the L-type $\mathrm{Ca}^{++}$ channels in the membrane of the SAN delaying the process of depolarization (Han et al., 1996). These data was previously discussed by several studies that conclude the action of muscrinic agonists is mediated through the induction of endogenous NO. At the same time inhibitors of NO production augments the positive chronotropic effects of B-adrenergic stimulation. Surprisingly, NO donor stimulates the cGMP production which increased the release of acetyl cholin from the vagal nerve terminals. Yoo et al. (1998) have reported that Sodium Nitroprosside (SNP) may decrease $\mathrm{I}_{\mathrm{f}}$ by cGMP dependent stimulation of PDE. The hypothesis was tested that a reduction in $\mathrm{I}_{\mathrm{f}}$ during adrenergic stimulation would translate to a decrease in heart rate.
Conversely, SNP increased heart rate at concentrations as high as $100 \mu \mathrm{M}$ transiently. The effect of SNP was abolished by guanylyl cyclase inhibition and was mimicked by the membrane permeable analogue of cGMP $8 \mathrm{Br}$-cGMP, suggesting that SNP was acting via release of NO and stimulation of guanylyl cyclase (rather than nitrosylation or generation of superoxide radicals caused by some NO donors (Sarkar et al., 2000).

Surprisingly, Musialek et al. (1997) concluded that, independent of the autonomic nervous system, application of exogenous NO causes a marked tachycardia due to guanylyl cyclase-cGMP dependent stimulation of $\mathrm{I}_{\mathrm{f}}$ in guinea pig SAN cells. Similar results have been observed in the cardiac denervated rabbit (Hogan et al., 1999a) and in human subjects when arterial blood pressure is held constant (Hogan et al., 1999b). NO increases heart rate via cGMP dependent inhibition of Phosphodiesterase 3 (PDE3) to increase cAMP, mobilisation of intracellular calcium and also by a direct action of cGMP itself (Musialek et al., 2000). These well documented pathways all contribute to an increase in $I_{f}$ (DiFrancesco and Tortora, 1991). However, inhibitors of protein kinase $\mathrm{G}$ or $\mathrm{I}_{\mathrm{CaL}}$ have no effect on the tachycardia caused by NO.

Also, continuous infusion of the L-arginine and slidenafil reduces the force of myocardial contraction. The negative inotropic effect was induced mostly by cGMP generation and consequently protein kinases activation. Most cells contain at least one of three cGMP-dependent protein kinases (cGKs): cGKI, cGKI, or cGKII (Lohmann et al., 1997) that are targeted by their amino termini to distinct substrates and are involved in the regulation of different cellular functions. Mammals have two cGK genes, prkg1 and prkg2, that encode cGKI and cGKII. cGKI is present at high concentrations in all smooth muscles, platelets, cerebellum, hippocampus, dorsal root ganglia, neuromuscular junction end plate and kidney. Low levels have been identified in cardiac muscle, vascular endothelium, granulocytes, chondrocytes, osteoclasts and diverse brain nuclei (Keilbach et al., 1992). The I $\alpha$ isozyme is found in lung, heart, Dorsal Root Ganglia (DRG) and cerebellum. Together with the I $\alpha$ isozyme, the I $\beta$ isozyme is highly expressed in smooth muscle, including uterus, vessels, intestine and trachea (Geiselhoringer et al., 2004).

This was concluded by Hare and Stamler (2005) which showed that NO modulates cardiac contractility and remodeling. The relative importance of $\mathrm{NO}$ effects 
mediated by cGMP-dependent and cGMP-independent pathways was discussed with controversial findings through cardiomyocyte-specific cGKI knockout mice study produced by Godecke et al. (2001) and Massion et al. (2003). They demonstrated that cGMP/cGKI contributes to the negative inotropic effect of NO in the juvenile as well as in the adult murine heart. However, the $\mathrm{NO} / \mathrm{cGMP} / \mathrm{cGK}$ I pathway does not appear to be involved in the negative inotropic action of acetylcholine. Similar findings were reported by Schroder et al. (2003) who claimed that cardiomyocytedirected overexpression of cGKIa augmented NO/cGMP inhibition but not muscarinic inhibition of Ltype $\mathrm{Ca}^{2+}$ channel activity.

Wollert et al. (2003) noted that in cGKI-deficient mice and suggested a mechanism for the negative inotropic action of cGKI, namely, the inhibition of Ltype $\mathrm{Ca}^{2+}$ channels. Thus it appears that cardiac contractility is inhibited by NO-stimulated cGMP. Conversely C-natruretic peptide produce positive inotropic effect through GKI-stimulated cGMP and both effects are mediated via cGKI. The opposing effects of cGKI on cardiac contractility might be explained through different subcellular microdomains of $\mathrm{NO} / \mathrm{cGMP} / \mathrm{cGKI}$ versus $\mathrm{CNP} / \mathrm{cGMP} / \mathrm{cGKI}$ signaling.

Another possible mechanism of the negative inotropic effect was documented by Geelen et al. (2000), who reported that sildenafil blocks the rapid component of the inward rectifier potassium channel and might prolong cardiac action potential. This could result in a proarrhythmic tendency or, via higher $\mathrm{Ca}^{2+}$ transients, increase myocardial oxygen consumption. This serious effect may require high doses of sildenafil, probably above the therapeutic level (Sugiyama et al. (2002).

Reducing the cardiac workload by reducing the heart rate and contractility may exerts a cardioprotective effects by decreasing myocardial oxygen demand, similar to the effect achieved by Badrenergic receptors blockade. Several studies have shown that NO, the natriuretic peptides, bradykinin, insulin and adrenomedullin, have infarct-limiting effects via NO generation and subsequent cGMP accumulation (Abdallah et al., 2006; Hamid and Baxter, 2005; 2006; Baxter and Ebrahim, 2002; Cheitlin et al., 1999; Swissa et al., 2002; Paulus and Bronzwaer, 2002; Phillips et al., 2000). Furthermore, recent study concluded that sildenafil citrate pretreatment augments myocardial functional recovery after an ischemic time relevant to clinical cardiac transplantation (Botha et al.,
2010). On the other hand, myocardial infarction has been reported following the use of Sildenafil (Velasquez Lopez et al., 2007).

In the resent study, the level of the myocardial enzymes AST, CK and LDH are significantly increased in the cardiac effluent fluid. The enzyme elevation is a sign of cardiomyocyte injury. This happened despite the vasorelaxation of the smooth muscle fibers produced by the cGMP. However, the oxidative stress induces the formation of ROS, which plays a central role in cardiac physiology and Pathophysiology. It is now well established that when the production of ROS exceeds the capacity of antioxidant defenses, oxidative stress will produce a harmful effect on the functional and structural integrity of biological tissues.. The biological effects of ROS-mediated reactions are due to their direct interaction with cellular lipids, proteins and DNA (e.g., nicking, base-pair mutations, rearrangements, deletions, insertions and sequence amplification), causing cell damage and death. ROS also causes lipid peroxidation, which results in damage to the cell membrane and the membranes of cellular organelles (Tuteja et al., 2004).

Also, Oldenburg et al. (2004) reviewed an agreement to our data. They concluded that cGMPelevating interventions may also exhibit negative inotropic effects that could antagonize effects of elevated cAMP (Oldenburg et al., 2004).

To the contrary of our findings, Wallis et al. (1999) reviewed that increased sarcoplasmatic concentrations of cAMP, occurring either as a result of partial PDE 1 inhibition by sildenafil or the cross-talk between PDE 5 and 3, could increase myocardial contractility. Sugiyama et al. (2002) reported an inhibitory effect of sildenafil on the cAMP-hydrolyzing activity of canine and bovine cardiac ventricular membrane preparations, which would support this concept. Also, Senzaki et al. (2001) reported evidence for PDE 5A expression in canine cardiomyocytes, which is still controversial with respect to human cardiomyocytes (Sugiyama et al., 2001). While a lower threshold for ventricular tachycardias was demonstrated in a pacing model of isolated swine right ventricles treated with a high dose of sildenafil combined with a nitric oxide donor decreased the force of contraction as a result of shortening in the diastolic filling period (Hamid et al., 2007).

\section{CONCLUSION}

In this study, we found that infusion of L-Arginine and Sildenafil citrate produced both negative 
chronotropic and negative inotropic effects which we believe due to the increased cGMP. These effects may exert a cardioprotective actions by reducing the myocardial contractility and the heart rate, thereby reducing the myocardial oxygen demand. This can be helpful to some patients suffering from Ischemic Heart Disease (IHD) but will be detrimental in situations where the systolic cardiac function is depressed.

\section{REFERENCES}

Ashman, D.F., R. Lipton, M.M. Melicow and T.D. Price, 1963. Isolation of adenosine 3', 5'-monophosphate and guanosine 3', 5'-monophosphate from rat urine. Biochem. Biophys. Res. Commun., 11: 330-334. PMID: 13965190

Balligand, J.L., L. Kobzik, X. Han, D.M. Kaye and L. Belhassen et al., 1995. Nitric oxide-dependent parasympathetic signaling is due to activation of constitutive endothelial (type III) nitric oxide synthase in cardiac myocytes. J. Biol. Chem., 270: 14582-14586. PMID: 7540173

Baxter, G.F. and Z. Ebrahim, 2002. Role of bradykinin in preconditioning and protection of the ischaemic myocardium. Br. J. Pharmacol., 135: 843-854. PMID: 11861312

Botha, P., G.A. MacGowan and J.H. Dark, 2010. Sildenafil citrate augments myocardial protection in heart transplantation. Transplantation, 89: 169177. DOI: $10.1097 /$ TP.0b013e3181c42b22

DiFrancesco, D. and P. Tortora, 1991. Direct activation of cardiac pacemaker channels by intracellular cyclic AMP. Nature, 351: 145-147. PMID: 1709448

Feil, R. and B. Kemp-Harper, 2006. cGMP signaling: From bench to bedside. EMBO Rep., 57: 149-153. DOI: $10.1038 /$ sj.embor.7400627

Feil, R., S.M. Lohmann, H. de Jonge, U. Walter and F. Hofmann, 2003. Cyclic GMP-dependent protein kinases and the cardiovascular system: Insights from genetically modified mice. Circ. Res., 93: 907-916. PMID: 14615494

Geelen, P., B. Drolet and J. Rail, 2000. Sildenafil citrate (Viagra) prolongs cardiac repolarization by blocking the rapid component of the delayed rectifier potassium current. Circulation, 102: 275-277.

Geiselhoringer, A., M. Gaisa, F. Hofmann and J. Schlossmann, 2004. Distribution of IRAG and cGKI-isoforms in murine tissues. FEBS Lett., 575: 19-22. DOI: 10.1016/j.febslet.2004.08.030
Godecke, A., T. Heinicke, A. Kamkin, I. Kiseleva and R.H. Strasser et al., 2001. Inotropic response to beta-adrenergic receptor stimulation and antiadrenergic effect of $\mathrm{ACh}$ in endothelial NO synthase-deficient mouse hearts. J. Physiol., 532: 195-204. PMID: 11368026

Hamid, S.A., M. Totzeck, C. Drexhage, I. Thompson, R.C. Fowkes and T. Rassaf et al., 2007. NO/cGMP pathway in adrenomedullin-mediated cardioprotection in mouse. J. Mol. Cell. Cardiol., 42: 1-195. DOI: 10.1007/s00395-009-0058-7

Han, X., L. Kobzik, J.L. Balligand, R.A. Kelly and T.W. Smith, 1996. Nitric Oxide Synthase $\left(\mathrm{NOS}_{3}\right)$ mediated cholinergic modulation of $\mathrm{Ca}^{2+}$ current in adult rabbit atrioventricular nodal cells. Circ. Res., 78: 998-1008. PMID: 8635250

Hare, J.M. and J.S. Stamler, 2005. NO/redox disequilibrium in the failing heart and cardiovascular system. J. Clin. Invest., 115: 509-517. PMID: 15765132

Hogan, N., B. Casadei and D.J. Paterson, 1999a. Nitric oxide donors can increase heart rate independent of autonomic activation. J. Applied Physiol., 87: 97-103. PMID: 10409562

Hogan, N., A. Kardos, D.J. Paterson and B. Casadei, 1999b. Effect of exogenous nitric oxide on baroreflex function in humans. Am. J. Physiol., 277: 221-227. PMID: 10409200

Hussain, M.B., R.J. MacAllister and A.J. Hobbs, 2001. Reciprocal regulation of cGMP-mediated vasorelaxation by soluble and particulate guanylate cyclases. Am. J. Physiol. Heart Circ. Physiol., 280: 1151-1159. PMID: 11179059

Jeremy, J.Y., S.A. Ballard and A.M. Naylor, 1997. Effects of sildenafil, a type-5 cGMP phosphodiesterase inhibitor and papaverine on cyclic GMP and cyclic AMP levels in the rabbit corpus cavernosum in vitro. Br. J. Urol., 79: 958-963. PMID: 9202566

Keilbach, A., P. Ruth and F. Hofmann, 1992. Detection of cGMP dependent protein kinase isozymes by specific antibodies. Eur. J. Biochem., 208: 467-473. PIMD: 13255910

Kojda, G. and K. Kottenberg, 1999. Regulation of basal myocardial function by nitric oxide. Cardiol. Res., 41: 514-523. PIMD: 10435023

Kuhn, M., 2004. Molecular physiology of natriuretic peptide signaling. Basic Res. Cardiol., 99: 76-82. PIMD: 14963665 
Kuo, J.F., B.K. Krueger, J.R. Sanes and P. Greengard, 1970. Cyclic nucleotide-dependent protein kinases. V. Preparation and properties of adenosine 3',5'monophosphate-dependent protein kinase from various bovine tissues. Biochim. Biophys. Acta, 212: 79-91. PIMD:4322697

Langendorff, O., 1895. Unverschungen and uber lebenden saugil hurherzen pfluger. Arch. Gis. Physiol., 61: 291.

Lincoln, T.M., N. Dey and H. Sellak, 2001. Invited review: cGMP-dependent protein kinase signaling mechanisms in smooth muscle: from the regulation of tone to gene expression. J. Applied Physiol., 91: 1421-1430. PIMD:11509544

Lohmann, S.M., A.B. Vaandrager, A. Smolenski, U. Walter and H.R. De Jonge, 1997. Distinct and specific functions of cGMP-dependent protein kinases. Trends Biochem. Sci., 22: 307-312. DOI: 10.1016/S0968-0004(97)01086-4

Lucas, K.A., G.M. Pitari, S. Kazerounian, I. RuizStewart and J. Park et al., 2000. Guanylyl cyclases and signaling by cyclic GMP. Pharmacol. Rev., 52: 375-414.

Massion, P.B., O. Feron, C. Dessy and J.L. Balligand, 2003. Nitric oxide and cardiac function: ten years after and continuing. Circ. Res., 93: 388-398. PIMD: 12958142

Musialek, P., L. Rigg, D.A. Terrar, J. Paterson and B. Casadei, 2000. Role of cGMP-inhibited phosphodiesterase and sarcoplasmic calcium in mediating the increase in basal heart rate with nitric oxide donors. J. Mol. Cell. Cardiol., 32: 1831-1840. PMID: 11013127

Musialek, P., M. Lei, F. Brown, D.J. Paterson and B. Casadei, 1997. Nitric oxide can increase heart rate by stimulating the hyperpolarization-activated inward current, I(f). Circ. Res., 81: 60-68. PMID: 9201028

National Institute of Health, 1996. Guide for the care and use of laboratory animals. DHEW Publication (NIH), Office of Science and Health Reports, DRR/NIH, Bethesda, MD.

Ockaili, R., V.R. Emani, S. Okubo, M. Brown and K. Krottapalli et al., 1999. Opening of mitochondrial $\mathrm{K}_{\mathrm{ATP}}$ channel induces early and delayed cardioprotective effect: Role of nitric oxide. Am. J. Physiol. Heart Circ. Physiol., 277: 2425-2434.

http://ajpheart.physiology.org/cgi/content/full/277/ 6/H2425
Oldenburg, O., Q. Qin, T. Krieg, X.M. Yang and S. Phillipp et al., 2004. Bradykinin induces mitochondrial ROS generation via NO, cGMP, PKG and mitoK $\mathrm{ATP}_{\mathrm{AT}}$ channel opening and leads to cardioprotection. Am. J. Physiol., 286: 468-476. PMID: 12958031

Sarkar, D., P. Vallance, C. Amirmansour and S.E. Harding, 2000. Positive inotropic effects of NO donors in isolated guinea-pig and human cardiomyocytes independent of NO species and cyclic nucleotides. Cardiovasc. Res., 48: 430-439. DOI: 10.1016/S0008-6363(00)00202-9

Schroder, F., G. Klein, B. Fiedler, M. Bastein and N. Schnasse et al., 2003. Single L-type $\mathrm{Ca}(2+)$ channel regulation by cGMP-dependent protein kinase type I in adult cardiomyocytes from PKG I transgenic mice. Cardiovasc. Res., 60: 268-277. PMID: 14613856

Senzaki, H., C.J. Smith and G.J. Juang, 2001. Cardiac phosphodiesterase 5 (cGMP-specific) modulates Badrenergic signaling in vivo and is down-regulated in heart failure. FASEB J., 15: 1718-1726. PMID: 11481219

Su, J., P.M. Scholz and H.R. Weiss, 2005. Differential effects of cGMP produced by soluble and particulate guanylyl cyclase on mouse ventricular myocytes. Exp. Biol. Med., 230: 242-250. PMID: 15792945

Sugiyama, A., N. Takeuchi, Y. Saegusa M. Sugita and K. Hashimoto, 2002. Molecular mechanisms of cardiostimulatory effects of sildenafil. Jap. J. Pharmacol., 88: 362-364. DOI: 10.1254/jjp.88.362

Sugiyama, A., Y. Satoh, H. Shiina A. Takahara and M. Yoneyama et al., 2001. Cardiac electrophysiologic and hemodynamic effects of sildenafil, a PDE5 inhibitor, in anesthetized dogs. J. Cardiovasc. Pharmacol., 38: 940-946. PMID: 11707698

Tuteja, N., M. Chandra, R. Tuteja and M.K. Misra, 2004. Nitric oxide as a unique bioactivesignaling messenger in physiology and pathophysiology. J. Biomed. Biotech., 4: 227-237. DOI: 10.1155/S1110724304402034

Wall, M.E., S.H. Francis, J.D. Corbin, K. Grimes and R. Richie-Jannetta et al., 2003. Mechanisms associated with cGMP binding and activation of cGMP-dependent protein kinase. Proc. Natl. Acad. Sci. USA., 100: 2380-2385. DOI: $10.1073 /$ pnas. 0534892100 
Wallis, R.M., J.D. Corbin, S.H. Francis and P. Ellis, 1999. Tissue distribution of phosphodiesterase families and the effect of sildenafil on tissue cyclic nucleotides, platelet function and the contractile responses of trabeculae carneae and aortic rings in vitro. Am. J. Cardiol., 83: 3-12. PMID: 10078537

Weiss, H.R., E. Rodriguez, J. Tse and P.M. Scholz, 1994. Effect of increased myocardial cyclic GMP induced by cyclic GMP-phosphodiesterase inhibition on oxygen consumption and supply of rabbit hearts. Clin. Exp. Pharmacol. Physiol., 2: 607-614. PMID: 7813120
Wollert, K.C., S. Yurukova, A. Kilic, F. Begrow and B. Fiedler et al., 2003. Increased effects of C-type natriuretic peptide on contractility and calcium regulation in murine hearts overexpressing cyclic GMP-dependent protein kinase I. Br. J. Pharmacol., 140: 1227-1236. DOI: 10.1038/sj.bjp.0705567

Yoo, S., S.H. Lee, B.H. Choi, J.B. Yeom, W.K. Ho and Y.E. Earm, 1998. Dual effect of nitric oxide on the hyperpolarization-activated inward current (I (f)) in sino-atrial node cells of the rabbit. J. Mol. Cell. Cardiol., 30: 2729-2738. PMID: 9990543 